\title{
Microbial analysis of water bodies near food industries
}

\author{
Anindita Deb Pal ${ }^{*}$ and Astha Jain ${ }^{2}$ \\ ${ }^{1}$ Department of Food Science and Nutrition Management, J. D. Birla Institute, Kolkata, India \\ ${ }^{2}$ Department of Food Science and Nutrition Management, J. D. Birla Institute, Kolkata, India \\ *Corresponding Author: deb_anindita@yahoo.com, Tel.: Tel.: 91-33-24755070, 24767340
}

Available online at: www.isroset.org

Received: 07/Mar/ 2019, Accepted: 09/Apr/ 2019, Online: 31/Apr/2019

\begin{abstract}
The quality of water and occurrence of water borne diseases are critical public health issues. The most serious public health risk associated with drinking water is microbiological contamination thereby making it a priority for water quality testing. The objective of the study was to assess the quality of drinking water by isolation and enumeration of organisms through microbiological examination. Water samples were collected from four different regions - North, South, East and Central Kolkata. Microbial and fermentation tests were performed in the collected water samples followed by confirmatory IMViC tests to detect the presence of microorganisms. Microbial estimations indicated the presence of coliforms in water which may lead to diseases like diarrhoea and gastrointestinal problems. The biochemical tests also displayed the occurrence of the members of the Enterobacteriaceae family including E.coli, Enterobacter sp and Klebsiella sp. These microorganisms deteriorate the quality of drinking water making it unfit for human consumption. Therefore, accurate testing of drinking water is crucial in maintaining the health and safety of inhabitants who rely on this resource.
\end{abstract}

Keywords - E. coli, Enterobacter sp, Klebsiella sp, Microbial analysis, Public health, Water quality

\section{INTRODUCTION}

21st century is century of pollution, global warming, insecurity and vulnerable health factors. Water pollution is one of the major concerns worldwide. This occurs when contaminants are discharged directly or indirectly into water bodies thereby affecting the aquatic flora and fauna. Moreover, human health is also influenced by polluted water [1]. While the total amount of water available in the world is constant and is generally said to be adequate to meet all the demands of mankind, its quality and distribution over different regions of the world is uneven leading to issues of scarcity and suitability. Additionally, the quantity of potable water is known to be limited [2]. Water of good drinking quality is of basic importance towards maintenance of proper human physiology and general wellbeing.

Industrial pollution is one of the leading causes of contamination and toxicity worldwide [3]. It not only affects the quality of drinking water but also has a deleterious impact on the soil microflora and aquatic ecosystems due to release of toxic effluents. Illegal discharges or accidental spillage has been shown to account for majority of the incidents of surface water pollution [4]. Food industries severely impact water quality. Systematic management of industrial run off is extremely essential for maintaining a balanced ecosystem [5]. Interestingly, pathogenic microorganisms constitute a significant contaminant of foodprocessing wastewaters, particularly from meat, poultry and seafood processing facilities [6, 7]. Water contaminated by microorganisms may contribute to a wide range of health disorders. This has been documented to be responsible for more than 200 diseases, including typhoid fevers and cancers, which often lead to fatal outcomes especially in developing countries. Common foodborne pathogens have readily been found to produce biofilms on surfaces [8]. Most foodborne illnesses are limited to brief episodes of diarrhea, nausea, vomiting, weakness, chills, sore mouth, blurred vision, muscle paralysis and aches or other acute gastrointestinal problems. However, a small portion of foodborne diseases are indeed fatal, thereby enhancing the chances of food mediated death $[4,9]$.

Coliform bacteria including E. coli, Enterobacter $s p$, Klebsiella sp and Salmonella $s p$ are members of the Enterobacteriaceae family and are known to be useful markers of fecal contamination. Coliform bacteria are often referred to as "indicator organisms" because they indicate the potential presence of disease-causing bacteria in water. The presence of these microorganisms in water not only guarantees the possibility of an associated illness but also indicates that a contamination pathway exists between a source of bacteria (surface water, septic system, animal waste, etc.) and the water supply. The existence of the above 
has also been associated with numerous pathological outcomes. E. coli is known to produce potentially lethal toxins and cause food poisoning, the symptoms of which being abdominal pain, watery stool, nausea, vomiting and fatigue. Enterobacter is responsible for various ailments including urinary and respiratory tract infections [10]. Moreover, Salmonella and Klebsiella sp have also been established as agents of food borne diseases [11].

Escherichia coli, a member of the Enterobacteriaceae family is a facultative anaerobic, gram-negative, non-spore-forming, rod-shaped bacterium possessing the enzyme $\beta$ glucuronidase. E. coli occurs naturally in the intestines of humans and other warm blooded animals. In human and animal feces, E. coli is found at a concentration of about $10^{9}$ per gram forming roughly $1 \%$ of the total biomass of the large intestine. In general terms, this microorganism survives for about 4-12 weeks in water containing a moderate microflora at a temperature of $15-18^{\circ} \mathrm{C}$. The presence of E.coli in water is considered as a good indicator of fresh fecal contamination [12]. Furthermore, rapid rate of proliferation along with the known developmental stages of this bacterium makes it a suitable indicator of water contamination [13]. Most bacteria in the coliform group do not cause diseases. However, greater number of coliforms indicates that more disease-causing bacteria may be present in the same. Since coliform bacteria usually persist in water longer than most disease-causing organisms, the absence of coliform bacteria leads to the assumption that the water supply is microbiologically safe to drink [14].

Although water plays a significant role in maintaining human health, it is also known to be carrier of many diseases. Globally, drinking water has been established as a primary transmission pathway for diarrheal pathogens [15]. The microbial contamination of drinking water constitutes a major concern worldwide being an important source of infection and mortality. Waterborne infectious diseases are those in which the pathogens are present in water and ingested when that water is consumed. These diseases mostly originate from water contaminated with human feces. Each year, more than 800,000 children younger than 5 years of age die from diarrhea mostly in developing countries. This accounts for $11 \%$ of the total deaths globally. Similar to many other diarrheal diseases, ingestion of contaminated food and water can result in diarrhea due to Diarrheagenic E. coli (DEC). The occurrence of DEC has been widely established in areas possessing inadequate drinking water and poor sanitation. Different sources of waters including drinking water, rivers, swimming pools, surface waters, and lakes have been found to harbor these organisms. Transmission of these pathogens usually occurs while drinking, bathing, and/or using water for food preparation. According to the water-quality standards provided by WHO, the number of $E$. coli bacteria should be nil in a $100 \mathrm{~mL}$ drinking water sample, although certain standards do allow the existence of ten coliforms $/ 100 \mathrm{~mL}$ potable water [16].

Drinking water pollution by fecal coliform bacteria harboring resistance genes is a water-quality affair of national importance. Coliform microorganisms can be considered as important vehicles for spread of resistance genes due to its abundance in such environments [16, 17]. The objective of this study was to determine the prevalence of microbial contaminants, especially the members of the Enterobacteriaceae family in water bodies of different regions of the city. The coliform group including $E$. coli and other bacteria were investigated in water bodies near industries which were being used as sources of drinking water. The study aims to interpret the microbiological safety of these water bodies for domestic uses and public health.

Rest of the paper is organized as follows: Section I contains the introduction of the topic, section II contains the related work, section III explains material and methods, section IV describes results and discussions, section $\mathrm{V}$ concludes the work carried out along with future directions.

\section{RELATED WORK}

In a study published in the Procedia Environmental Sciences, the effluents of sugar and textile industry have been proved to have deleterious effects on the soil microflora, culminating in abnormal Biochemical Oxygen Demand (BOD) and Chemical Oxygen Demand (COD) [18]. As mentioned in the International Journal of Innovative Research in Computer and Communication Engineering, 1.8 million people have been estimated to die each year as a result of severe diarrhoea caused by drinking contaminated water. Contamination of water is a major cause for outbreak of enteric diseases. Furthermore, approximately 580 people die of water pollution related illnesses each day in India.

\section{Methodology}

Selection of sample: Water samples were collected from aqueous bodies near food industries of North, South, East and Central Kolkata in containers previously autoclaved and sterilized at $121^{\circ} \mathrm{C}$ and $15 \mathrm{psi}$ (Table 1).

Table 1: Water samples analyzed

\begin{tabular}{|c|c|c|}
\hline $\begin{array}{c}\text { Different regions } \\
\text { in Kolkata }\end{array}$ & Sample codes & $\begin{array}{c}\text { Number of } \\
\text { samples taken }\end{array}$ \\
\hline North & N1 \& N2 & 2 \\
\hline South & S1 \& S2 & 2 \\
\hline East & E1 \& E2 & 2 \\
\hline Central & C1 \& C2 & 2 \\
\hline \multicolumn{2}{|c|}{ Total } \\
\hline
\end{tabular}

Preparation of microbiological media, pour plating and spread plating: The samples collected and stored in 
sterilized bottles were brought to room temperature and used for analysis. Bacteriological enumeration and characterization was carried out for indicator organisms' i.e. total and fecal coliform by plating on selective, differential as well as enrichment medias respectively. Nutrient agar medium was used as a general purpose, non selective media to culture all microbial cells. Eosine Methylene Blue agar medium (EMB) and MacConkey agar was used for the isolation, enumeration, and differentiation of Enterobacteriaceae. The inoculated plates were incubated at $37^{\circ} \mathrm{C}$ for 24 hours for observation of microbial growth. The results were expressed as Colony Forming Units per millilitre $(\mathrm{CFU} / \mathrm{ml})$.

Fermentation Tests: Lactose and sucrose fermentation tests were performed in the samples to test for the presence of coliforms. The samples were inoculated in Durhams tube and incubated for 24 hours at $37^{\circ} \mathrm{C}$. Phenol red was used as an indicator. A yellow colour post addition of indicator along with appearance of gas bubbles indicated a positive fermentation test.

IMViC Tests: IMViC, a series of four tests namely Indole, Methyl red, Voges Proskauer and Citrate utilization test were carried out for the confirmation of coliform types. The tests were conducted based on protocols mentioned by V. Hemraj et al. ${ }^{[17]}$

Statistical Analysis: Results were quantified as mean \pm s.d.and expressed as $\mathrm{CFU} / \mathrm{ml}$. p values were estimated using the GraphPad software (California, USA). $5 \%$ level of significance and $90 \%(* *), 95 \%(* *)$ and $99 \%(*)$ confidence intervals have been considered to be statistically significant.

\section{RESUlts AND Discussion}

\section{Enumeration of microorganisms in water}

A variety of microorganisms were observed on nutrient agar medium since it supports the growth of all kinds of microorganisms. Therefore, specific agars were used to examine the species of microorganisms in water. Two different medias, EMB agar and MacConkey agar were used to differentiate the microorganisms in water. EMB agar was used because it is a selective and differential agar medium used for isolation of coliforms. MacConkey agar was used as another media for selective isolation of gram negative bacteria and differentiation of the members of Enterobacteriaceae as lactose fermenters or non fermenters. Table 2 shows the number of colonies in nutrient agar, EMB and MacConkey agar which are expressed as mean \pm SD.
Table 2: Number of colonies in Nutrient Agar, EMB and MacConkey Agar

\begin{tabular}{|c|c|c|c|}
\hline \multirow{2}{*}{ Number of } & \multicolumn{3}{|c|}{ Number of colonies (CFU/ml) } \\
\cline { 2 - 4 } & $\begin{array}{c}\text { Nutrient } \\
\text { Agar }\end{array}$ & EMB Agar & $\begin{array}{c}\text { MacConkey } \\
\text { Agar }\end{array}$ \\
\hline North & $392 \pm 1.41 * *$ & $68 \pm 0 * *$ & $28 \pm 2.21 * *$ \\
\hline South & $280 \pm 1.41 * *$ & $32 \pm 2.12 * *$ & $27 \pm 1.41 * *$ \\
\hline East & $272 \pm 1.41 * *$ & $56 \pm 2.12 * *$ & $38 \pm 0.70^{* *}$ \\
\hline Central & $52 \pm 2.82 *$ & $17 \pm 2.12 * *$ & $13 \pm 0.70 * *$ \\
\hline
\end{tabular}

\section{Result expressed as (mean $\pm S D) \quad C F U / m l$ \\ $* P<0.05$ considered as statistical significant}

Nutrient agar displayed the presence of microorganisms in all the water samples analyzed. As shown in Table 2, the number of colonies observed in EMB agar in samples from North Kolkata was found to be 68,32 in samples from South, 56 in samples from East and 17 in samples from Central Kolkata. Appearance of dark purple coloured colonies in EMB agar indicated the presence of lactose fermenters, Klebsiella sp and E.coli whereas appearance of colourless colonies indicated the presence of non lactose fermenter including Salmonella, Pseudomonas aeruginosa and Shigella.

The number of colonies observed in MacConkey agar was found to be 28 in samples from North Kolkata, 27 in samples from South, 38 in samples from East and 13 in samples from Central Kolkata. Red and pink colonies in MacConkey agar are consistent with the characteristics displayed by $E$. coli, Klebsiella pneumonia, Enterobacter aerogenes, Staphylococcus sp and Enterococcus sp whereas colourless colonies indicated the presence of Pseudomonas aeruginosa in the water samples.

\section{Fermentation tests}

Fermentation test is the most common biochemical analysis used for detection of Enterobacteriaceae family, especially coliforms. This tests the bacteria's ability to ferment lactose and sucrose and produce acidic end products. A yellow colour post addition of indicator along with appearance of gas bubbles in the tube indicates a positive test for lactose and sucrose fermentation. A negative result shows no colour change. Table 3 shows the ability of the bacteria to ferment both lactose and sucrose. Positive lactose fermentation indicated the presence of Klebsiella sp and E. coli and negative test signified the presence of Enterobacter sp. Also, negative result for sucrose fermentation designated the presence of Klebsiella sp and Salmonella sp. Furthermore, gas bubbles were also observed in the Durham's tubes which indicated gas production as the result of fermentation. 
Table 3: Fermentation analysis

\begin{tabular}{|c|c|c|}
\hline Sample & $\begin{array}{c}\text { Lactose } \\
\text { fermentation }\end{array}$ & $\begin{array}{c}\text { Sucrose } \\
\text { fermentation }\end{array}$ \\
\hline North & Positive & Negative \\
\hline South & Positive & Negative \\
\hline East & Positive & Negative \\
\hline Central & Negative & Negative \\
\hline
\end{tabular}

\section{IMVic Analysis}

Following presumptive isolation of coliforms, further testing is required for confirmation of the type of coliform bacteria. Since bacterial organisms are similar in morphological and cultural characteristics, IMViC tests were used as a confirmatory test to differentiate between these bacteria.

Table 4: IMViC tests of the water samples

\begin{tabular}{|c|c|c|c|c|}
\hline Samples & $\begin{array}{c}\text { Indole } \\
\text { test }\end{array}$ & $\begin{array}{c}\text { Methyl } \\
\text { red } \\
\text { test }\end{array}$ & $\begin{array}{c}\text { Voges } \\
\text { proskauver } \\
\text { test }\end{array}$ & $\begin{array}{c}\text { Citrate } \\
\text { utilization } \\
\text { test }\end{array}$ \\
\hline N1 & Positive & Positive & Negative & Positive \\
\hline N2 & Negative & Positive & Negative & Positive \\
\hline S1 & Positive & Positive & Negative & Positive \\
\hline S2 & Negative & Positive & Negative & Negative \\
\hline E1 & Positive & Positive & Positive & Positive \\
\hline E2 & Positive & Positive & Positive & Positive \\
\hline C1 & Negative & Positive & Negative & Positive \\
\hline C2 & Positive & Positive & Positive & Negative \\
\hline
\end{tabular}

IMViC is a series of four tests i.e. Indole, Methyl Red, Voges Prosekaeur, and Citrate Utilization tests which is carried out for identification of the members of Enterobacteriaceae family. This is done in accordance with the changes in colour of the medium on addition of the respective indicators. Majority of organisms showed Indole test positive, Methyl Red positive, Voges Proskauver negative and Citrate test positive, thereby positively indicating the presence of E.coli and Klebsiella sp in water samples (Table 4). Some organisms also displayed a negetive Indole and a positive Voges Proskauver test consistent with the characteristics of Enterobacter $s p$ in the water samples.

Based on above microbial as well as biochemical analysis, it can be inferred that the water samples indicated the presence of various coliform microorganisms including E.coli, Klebsiella $s p$ and Enterobacter sp. Therefore, the water samples tested are non portable and may lead to adverse health consequences if consumed directly.

\section{Discussion}

An adequate supply of safe drinking water is universally recognized as a basic human requirement. Previous reports have indeed documented that improving the microbial quality of drinking water by household treatment and safe storage reduces the development of diarrhea [15]. Yet millions of people in the developing world do not have ready access to an adequate and safe water supply owing to rapid urbanization, mostly in peri-urban and slum areas. The old water distribution and sewage disposal systems in addition to poor sanitation facilities generally facilitate the spread of fecal bacteria to surface and drinking water thereby contributing towards waterborne illnesses [16].

The bacteriological analysis of water determines the potability of water. According to Indian standard (BIS, 1981), $95 \%$ water samples are supposed to be devoid of any coliform organisms. However, bacteriological analysis of drinking water of several areas does exhibit contamination with members of the Enterobacteriaceae family along with other pathogens [18]. Presence of E. coli and other coliform bacteria reflect a poor quality of drinking water. Old water distribution networks, leakages in pipeline, inadequate sanitary condition and improper management of waste disposal have chiefly been identified as the main culprits of the above. Old pipes and leakages in pipes provide a passage to waste water and other pollutants thereby altering the quality and raising the probability of deleterious health outcomes in the consumers [19].

In the present study, results from the differential agars and microbial analysis revealed the contamination of water samples with microorganisms including E.coli, Proteus $s p$, Klebsiella sp, Salmonella sp and Enterobacter sp. Therefore, water samples analyzed were found to unfit for direct consumption. Contaminants in water can affect water quality and consequently human health. Also, the risk of acquiring a waterborne infection accelerates with the increase in the level of contamination by pathogenic microorganisms.

\section{CONCLUSION ANd Future Scope}

Clean water is poorly located and distributed, the result being that people continue to use a closer and contaminated source. Inadequate access to water has a serious impact on the wellbeing of the population. Contaminants in water can affect water quality and consequently human health. Also, the risk of acquiring a waterborne infection has been positively correlated with the amount of pathogenic microorganisms. Microbiological parameters are very important in water resources in terms of public health since they play a significant role in the transmission of enteric diseases. Thus, the present study determined the safety of water bodies near industries. The present study did display the presence of disease causing microorganisms in water. Therefore, direct consumption of the same without any decontamination measures may negatively impact the fitness of the consumers. Frequent quality analysis of drinking water is essential for maintenance of overall health. The current 
analysis therefore attempts to contribute to the limited researches carried out for assessment of water safety in view of increasing public health awareness. Education of the population on simple domestic scale water purification in future may help in improving the general health status.

\section{ACKNOWLEDGMENT}

The authors are thankful to J. D. Birla Institute for providing all the necessary reagents and laboratory facilities to carry out the study.

\section{CONFLICT OF INTEREST}

The authors declare no conflict of interest.

\section{SOURCE OF FUNDING}

This work was self funded as part of the dissertation project of the author.

\section{REFERENCES}

[1]. C.M. Noorjahan, "Physicochemical characteristics, identification of bacteria and biodegradation of industrial effluent", Journal of Bioremediation and Biodegradation, Vol.5, No.3, pp.1-5, 2014.

[2]. S.S. Purewal, N. Kumar, P. Ganguly, and M.K. Jogi, "Qualitative analysis of water samples collected from different locations of Jaipur, Rajasthan, India", International Journal of Current Research, Vol.6, No.3, pp.5681-5683, 2014.

[3]. S. Gyawali, K. Techato, and C. Yuangyai, "Effects of Industrial Waste Disposal on the Surface Water Quality of U-tapao River, Thailand", In the Proceedings of the 2012 International Conference on Environment Science and Engineering, pp.109-113, 2012.

[4]. D. Briggs, "Environmental pollution and the global burden of disease", British Medical Bulletin, Vol.68, No.1, pp.1-24, 2003.

[5]. L.S. Durge, A.M. Chilke, and R.N. Chavhan, "Physico-Chemical Analysis of Waste Water from ACC Cement Industry from an Industrial Town - Ghugus (Maharashtra), India", International Journal of Scientific Research in Biological Sciences, Vol.6, No.1, pp.240-242, 2019.

[6]. T.G. Amabye, "Effect of food processing industries effluents on the environment: A case study of MOHA Mekelle bottling company, Tigray, Ethiopia", Industrial Chemistry, Vol.1, No.2, pp.1-4, 2015.

[7]. A. Husain, M.M. Ashhar, and I. Javed, "Analysis of industrial wastewater in Aligarh city", Journal of Chemical and Pharmaceutical Research, Vol.6, No.1, pp.614-621, 2014.

[8]. U. Szewzyk, R. Szewzyk, W. Manz, and K.H. Schleifer, "Microbiological safety of drinking water", Annual Review of Microbiology, Vol.54, pp.81-127, 2000.

[9]. L. Manning, "The impact of water quality and availability on food production", British Food Journal, Vol.110, No.8, pp.762-780, 2008.

[10]. M. Barabde, and S. Danve, "Real time water quality monitoring system", International Journal of Innovative Research in Computer and Communication Engineering, Vol.3, No.6, pp.5064-5069, 2015.

[11]. M.M. Bumadian, H.H. Almansury, I.H. Bozakouk, Y.F. Lawgali, and F.L. Bleiblo, "Detection and enumeration of coliform bacteria in drinking water at hospital of Benghazi/Libya", Journal of Experimental Biology and Agricultural Sciences, Vol.1, No.6, pp.436-440, 2013.

[12]. H. Seckin, "Investigation of Coliform And E. Coli Bacteria And Nitrite And Nitrate Levels In Drinking Waters of Van And Some
Provinces", International Organization of Scientific Research Journal of Environmental Science, Toxicology and Food Technology, Vol.12, No.14, pp.47-50, 2018.

[13]. R.T. Murray, R.E. Goldstein, E.F. Maring, D.G. Pee, K. Aspinwall, S.M. Wilson, and A.R. Sapkota, "Prevalence of Microbiological and Chemical Contaminants in Private Drinking Water Wells in Maryland, USA", International Journal of Environmental Research and Public Health, Vol.15, No.1686, pp.1-13, 2018.

[14]. J.S. Gruber, "Coliform Bacteria as Indicators of Diarrheal Risk in Household Drinking Water: Systematic Review and MetaAnalysis", PLoS One, Vol.9, No.9, pp.1-14, 2014.

[15]. A.E. Fakhr, "Impact of Some Ecological Factors on Fecal Contamination of Drinking Water by Diarrheagenic AntibioticResistant Escherichia coli in Zagazig City, Egypt", International Journal of Microbiology, Vol.2016, No.3, pp.1-9, 2016.

[16]. A. Haleem, "Evaluation of Microorganisms of Drinking Water of Rafha City, Northern Borders, Saudi Arabia", Journal of Cytology and Histology, Vol.7, No.3, pp.1-7, 2016.

[17]. V. Hemraj, D. Sharma, and A. Gupta, "A review on commonly used biochemical test for bacteria", Innovare Journal of Life Science, Vol.1, No.1, pp.1-7, 2013.

[18]. A. Kaur, S. Vats, S. Rekhi, A. Bhardwaj, J. Goel, R.S. Tanwar, and K.K. Gaur, "Physico-chemical analysis of the industrial effluents and their impact on the soil microflora", Procedia Environmental Sciences, Vol.2, pp.595-599, 2010.

[19]. R. Amin, S.S. Ali, Z. Anwar, and J.Z.K. Khattak, "Microbial Analysis of Drinking Water and Water Distribution System in New Urban Peshawar", Current Research Journal of Biological Science. Vol.4, No.6, pp.731-737, 2012.

\section{AUTHORS PROFILE}

Dr. Anindita Deb Pal completed Masters in 2009 with a specialization in BioMedical Science from University of Delhi. She has been awarded with fellowships (UGC-JRF and SRF) and Ph.D. Degree in Biotechnology by University of Calcutta, India in 2015. At present she is working as an Assistant

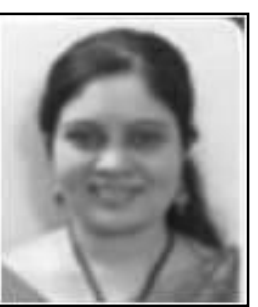
Professor in the Department of Food Science and Nutrition Management at J. D. Birla Institute, Kolkata. She has published several papers in journals of repute. Her main research work focuses on Food Science and Microbiology. She has 5 years of teaching experience and 4 years of research experience.

Ms. Astha Jain completed her B.Sc in Food Science and Nutrition Management from J. D. Birla Institute, Jadavpur University in 2016 and M.Sc in 2018 with a specialization in Food and Nutrition. She is currently working as a Clinical Dietician in Bhagirathi Neotia Woman and Child Care Centre,

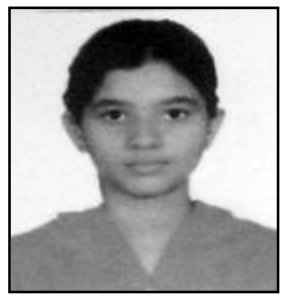
Kolkata. 